\title{
Testing your lungs: spirometry
}

\section{What is spirometry?}

A spirometry test measures how healthy your lungs are and can be used to help diagnose and monitor lung conditions. During the test, you will breathe out as much air as you can, as hard as you can, into a device called a spirometer. The test measures how much air you can blow out in total and how much air you can blow out in the first second of the test. The test should not be painful and usually takes less than 10 minutes.

\section{Should you take a test?}

Yes, if:

- You smoke, or you used to smoke

- You cough a lot

- You become short of breath when walking quickly

- You are worried about the health of your lungs

- You are already receiving treatment for a lung condition

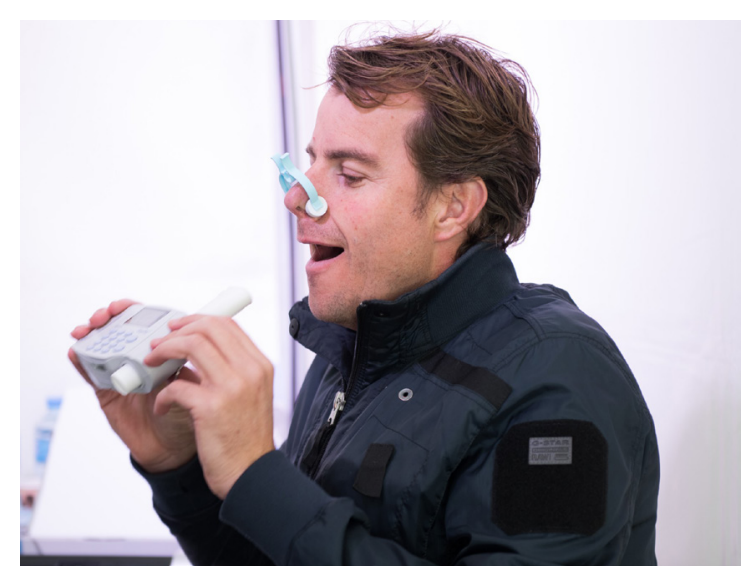

\section{What happens during the test?}

Your healthcare professional will show you how to blow into the spirometer before you begin. You may need to wear a soft clip over your nose to stop air leaking out of your nostrils. Before starting the test, you might be asked to breathe in deeply and out gently into the spirometer. You will then be asked to blow at least three times, but usually no more than 10 times, into the spirometer.

During the spirometry test, you must:

- Breathe in as deeply as you can and place your lips tightly around the mouthpiece.

- Try your hardest and blast out your air as quickly as possible.

- Keep blowing out until your lungs are empty and your healthcare professional tells you to stop. 


\section{Understanding your results}

Your healthcare professional will use your results (FEV1 and FVC) to decide how well your lungs are working. If the amount of air you can blow out during the first second is low, you may have a narrowing of your airways, possibly due to asthma or chronic obstructive lung disease (COPD). If you are already receiving treatment for asthma or COPD (such as an inhaler), the spirometry test can be used to check that the treatment is helping your lungs to work as well as possible. The test may also be useful to rule out some other lung conditions.

Healthcare professionals use charts to understand how your results compare to a "normal measurement". Imagine that 100 people of the same age, sex and height as you had taken the test, you can see where your results fit within this group and therefore how healthy your lungs are.

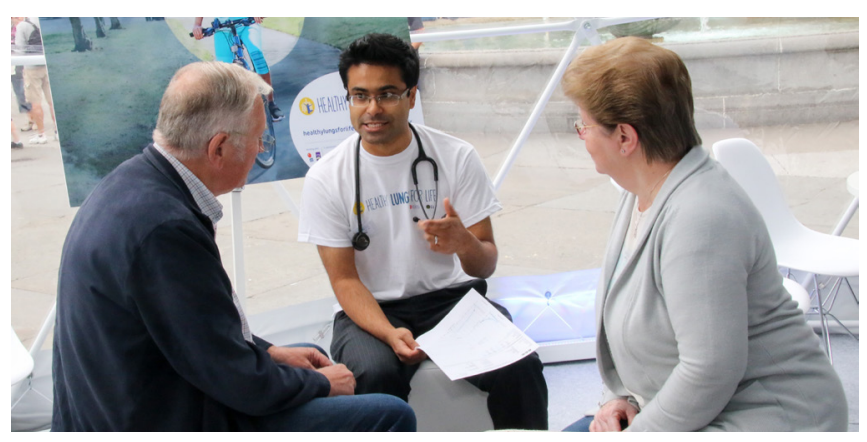

The lung growth charts were developed by the Global Lung Function Initiative using information on lung function from people around the world.

\section{What does this mean for your results?}

For every person, there is a range of results that is considered normal for your age and height.

For example, if your lung function was normal for your age, height, sex and ethnic background it may look like the picture on the left. However, if you a had lung condition that needed treatment it may look like the picture on the right.
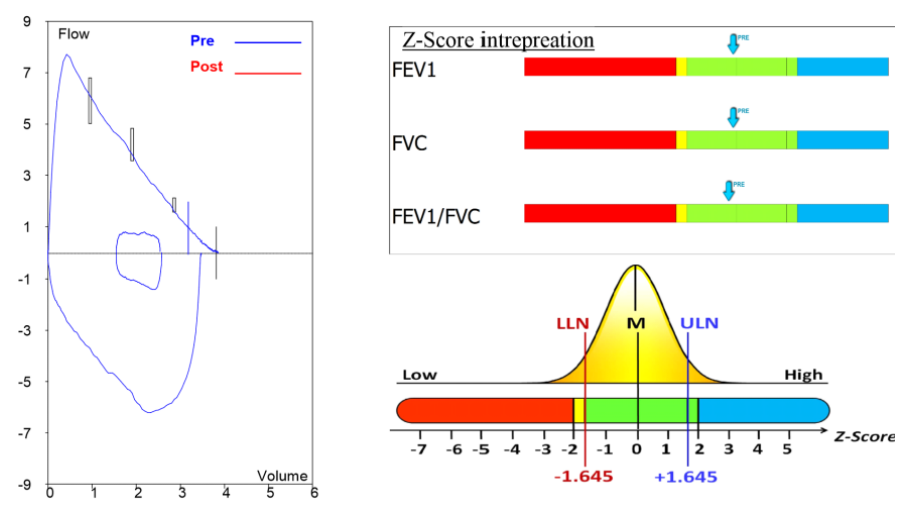

Spirometry results for a person with normal lung function for their age, height, sex and ethnic background
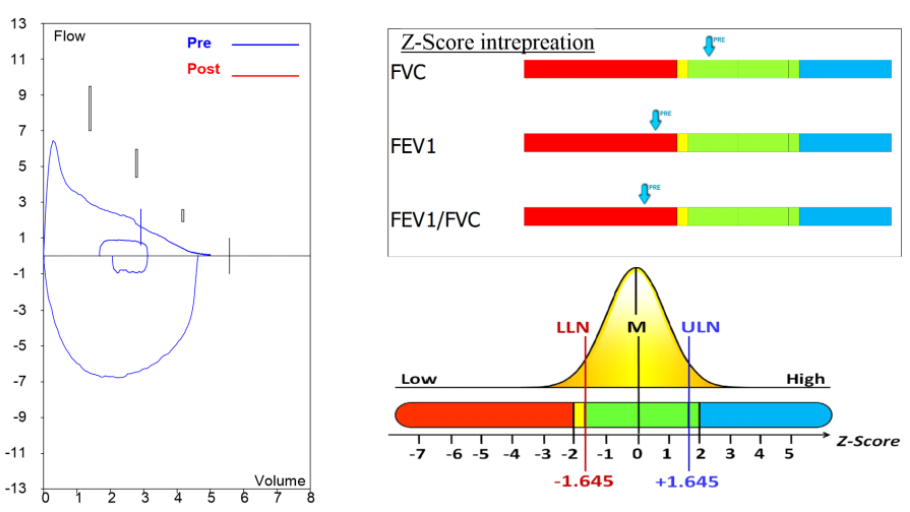

Spirometry results for a person that may have a lung condition that needs treatment 


\section{How should you prepare for the test?}

The results of your test could be affected by certain activities, like smoking, drinking coffee, doing strenuous exercise and eating a large meal, beforehand.

If you take medications for a lung condition, you may be asked to not use them for a set amount of time before the test.

Ask your healthcare professional in advance of the test how you can prepare.

\section{Problems you might have during the test}

The hard blows needed for this test are difficult for some people. If you become tired or lightheaded during the test, ask for a couple of minutes to catch your breath before trying again. Some people may find that the test makes them want to cough. If this happens, try and clear your chest before you try again.

\section{What happens if the test results look abnormal or if you have a lung condition?}

Your healthcare professional may ask you to inhale a medication that helps with breathing, wait 10-15 minutes and then repeat the test. This helps them to see whether any damage to the lungs is reversible and whether a prescription for an inhaler is likely to improve your breathing.

How you respond to this medication, known as a bronchodilator, may also help the doctor to tell whether you have asthma (which will improve after the bronchodilator) or COPD (which shows less improvement).

\section{My test results are normal - does that mean I am healthy?}

If you have had asthma-like symptoms in the past but the results of your spirometry test are normal, you may still have asthma.

If you smoke, or breathe in hazards like dusts, smoke, fumes or chemicals at work, and your results are normal, you are still at a high risk of different lung conditions and should do as much as you can to protect your lungs.

It is never too late to give up smoking, and there is support available - ask your healthcare professional how they can help you to quit. The ELF website has lots of information and tips on quitting smoking which you can download in a range of languages, so this could be a good place to start. 


\section{Will I need any more tests?}

The spirometry test is an important measure of lung function. If your symptoms vary (for example with asthma) you may be asked to repeat the test at different times, in which case you could take note of your results so you know what is a normal result for you. If you have an ongoing lung condition regular spirometry may be used to monitor it. In addition, you may be asked to carry out some more tests if the doctor needs to investigate further. further. Spirometry can also be part of other lung function testing, like an exercise test or a bronchial challenge test.

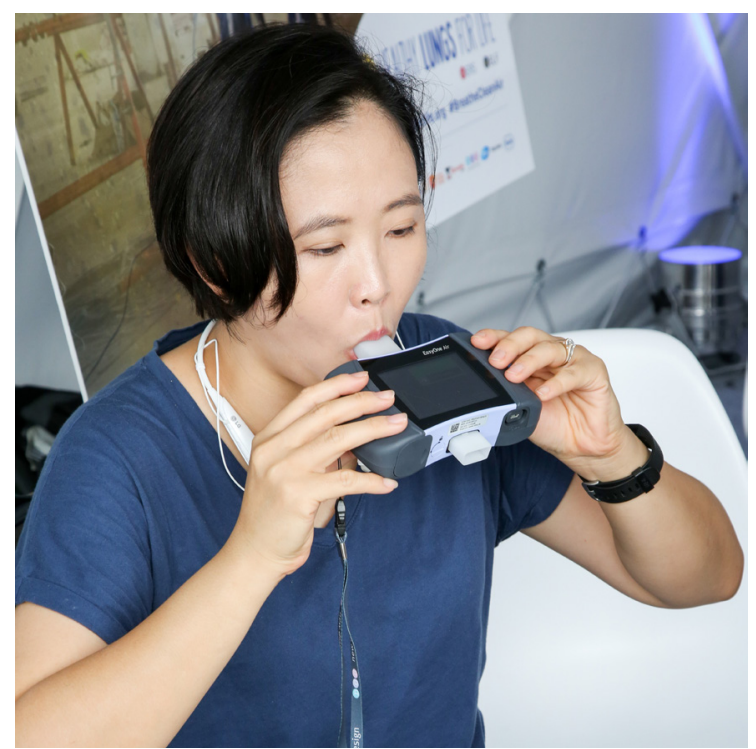

\section{Further reading}

- European Lung Foundation website: www.europeanlung.org For more information on lung conditions and how to look after your lungs.

- Healthy Lungs for Life website: www.healthylungsforlife.org Find out more about the Healthy Lungs for Life campaign, and get information information on the importance of clean air, physical activity and stopping smoking for your lungs.

\section{- Global Lung Function Initiative:} www.ers-education.org/guidelines/global-lung-function-initiative Learn more about the Global Lung Function Initiative, through which a group of researchers and clinicians are developing reference values for lung function tests to make sure that your test result is accurate, by collecting information on lung function from people around the world.

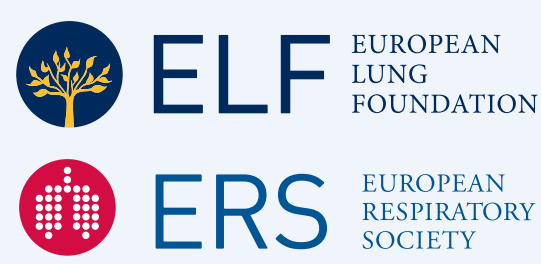

The European Lung Foundation (ELF) was founded by the European Respiratory Society (ERS), with the aim of bringing together patients, the public and respiratory professionals to positively influence respiratory medicine. ELF is dedicated to lung health throughout Europe, and draws together the leading European medical experts to provide patient information and raise public awareness about lung disease.

This material was originally compiled with the help of ERS spirometry expert Paul Enright, MD. It was reviewed in July 2018 as part of the Global Lung Function Initiative with the help of Sanja Stanojevic, PhD and Professor Graham Hall. 